SOCIAL SCIENCE RESEARCH

Michal Grajek

Estimating Network Effects and Compatibility in Mobile Telecommunications

SP || $2003-26$

December 2003

ISSN Nr. $0722-6748$

Research Area

Markets and Political Economy

Research Unit

Competitiveness and Industrial Change
Forschungsschwerpunkt

Markt und politische Ökonomie

Abteilung

Wettbewerbsfähigkeit und industrieller Wandel 
Zitierweise/Citation:

Michal Grajek, Estimating Network Effects and

Compatibility in Mobile Telecommunications, Discussion

Paper SP II 2003 - 26, Wissenschaftszentrum Berlin, 2003.

Wissenschaftszentrum Berlin für Sozialforschung gGmbH,

Reichpietschufer 50, 10785 Berlin, Germany, Tel. (030) 25491 - 0

Internet: www.wz-berlin.de 


\section{ABSTRACT \\ Estimating Network Effects and Compatibility in Mobile Telecommunications}

by Michal Grajek*

This paper provides empirical evidence on the extent of network effects and compatibility between networks in mobile telecommunications. We specify a structural model of demand for mobile telephone service, which allows us to identify the parameters of interest from the S-shape of mobile service diffusion. The network effects are measured by the dependence of consumer willingness to pay on the installed base of subscribers. Compatibility is measured by the relative extent of cross- and own-network effects. As such, it indicates whether the network effects operate at the firm level, at the industry level, or at both. We then estimate this model for the Polish mobile telephone industry using quarterly panel data for the period 1996-2001. We find strong network effects, which give rise to upward-sloping demand, and, despite full interconnection of the mobile telephone networks, low compatibility. We show also that ignoring network effects in empirical models of emerging network industries might substantially bias downward the estimated price elasticity of demand.

Keywords: Structural Econometric Model, Network Effects, Compatibility, Mobile Telecommunications

JEL Classification: C51, D12, L96

I thank Vivek Ghosal, Paul Heidhues, Eugenio Miravete and Lars-Hendrik Röller for their helpful comments. 


\section{Schätzung von Netzwerkeffekten und Kompatibilität in Mobilfunktelekommunikation}

Der vorliegende Beitrag bietet empirische Evidenz für den Umfang von Netzwerkeffekten und Netzwerkkompatibilität in der Mobilfunktelekommunikation. Wir spezifizieren ein strukturelles Modell für die Nachfrage von Mobilfunkdienstleistungen, das die Parameter von Interesse mithilfe der Sförmigen Funktion der Dienstleistungsdiffusion identifiziert. Die Netzwerkeffekte werden durch die Abhängigkeit der Zahlungsbereitschaft der Konsumenten von der installierten Abonnentenbasis gemessen. Netzwerkkompatibilität wird durch den relativen Umfang der Quer- und Eigen-Netzwerkeffekte gemessen. Sie weist darauf hin, ob Netzwerkeffekten auf Unternehmensebene, auf Industrieebene, oder auf beiden Ebenen bestehen. Dann schätzen wir das Modell für die Polnische Mobilfunkindustrie mit vierteljährlichen Paneldaten für 1996-2001. Wir stellen starke Netzwerkeffekte fest, die eine positive Steigung in der Nachfragefunktion verursachen, und - trotz der technisch vollständigen Querverbindung der Mobilfunknetze - niedrige Kompatibilität. Wir zeigen auch, dass das Übersehen von Netzwerkeffekten in empirischen Modellen von neuen Netzwerkindustrien die geschätzte Preiselastizität der Nachfrage signifikant nach unten verzerren kann. 


\section{Introduction}

Economic literature showed that consumption network effects could have important implications for size and structure of the underlying market, as well as for its competitiveness. ${ }^{1}$ A good is characterized by network effects when an increase in the number of users of the good increases its value to other users. Although the concept gave rise to numerous theoretical developments, it still remains largely unexplored in the empirical literature. This paper aims to fill this gap by providing empirical evidence on the extent of network effects from mobile telecommunications. We specify and estimate a structural model of consumer demand for mobile telephone service, which allows us to identify the extent of network effects and compatibility among competing networks. We emphasize the fact that structural approach, as opposed to reduced form approach, gives a scope for testing economic significance of the effects.

The concept of compatibility is closely linked to that of network effects. In an economic context, we might define compatibility as a measure, which says to what extent utility derived by users of a given network good is influenced by the number of users of competing network goods. As such, it is a very important characteristic of network industries. For instance, it greatly influences the nature of competition. We expect incompatible networks to aggressively compete for a market, whereas compatible networks compete more "traditionally", in a market, because the threat of tipping is reduced. ${ }^{2}$ To the best of our knowledge, this is the first study that assesses compatibility within an econometric framework.

It is important to stress that technological compatibility is not a sufficient condition for economic compatibility defined above. Although the mobile telephone networks that we study are fully interconnected, it is not clear a priori whether they are compatible or not. The most obvious reason for incompatibility involves intra-network discounts, which enhance relative attractiveness of own network to its subscribers. In the next section, we put forward several possible sources of network effects in mobile telecommunications. Some of them imply more compatible, while the other more incompatible networks. An estimate of compatibility allows us therefore additionally to discriminate among various possible sources of network effects.

The approach we follow draws on a model introduced in Grajek (2002). The main idea facilitating identification of network effects is that strong network effects might give rise to an

\footnotetext{
${ }^{1}$ See e.g. Katz and Shapiro (1994) for a general overview of the properties of markets fetured by network effects .

${ }^{2}$ Ibid.
} 
S-shaped diffusion of adoptions. ${ }^{3}$ The network effects in our economic framework are captured by the dependence of consumer willingness to pay on installed base of subscribers. Together with price changes, the installed base determines speed of diffusion of mobile telephone service in a population. Estimating structural state equations describing evolution of subscriptions, we are able to disentangle the price effect from the network effects.

We estimate the model using quarterly panel data from the Polish mobile telephone industry for the period 1996-2001. We find strong network effects, which give rise to an upward sloping part in the inverse demand function. The estimated degree of compatibility is surprisingly low. This suggests that subscribers to a given mobile network attach relatively little value to competing networks' subscribers. Simulations of the estimated model with alternative values of network effect and compatibility parameters illustrate their economic significance. We also estimate a restricted model, which does not account for network externalities. Estimated price elasticity of demand is much higher (in absolute terms) in this model, since we falsely attribute changes in demand due to network effects to changes in price. As we show also formally, ignoring network effects in empirical models of emerging network industries can substantially bias downward the estimated elasticity of demand.

The rest of the paper is organized as follows. Section 2 proposes several possible sources of network effects in mobile telecommunications. Section 3 contains description of the Polish mobile telephone industry and related research. In section 4, we specify the model and show that all structural parameters are identified from regression coefficients. Data and estimation issues are discussed in section 5 and section 6 interprets the results. The final section concludes.

\section{Network externalities in mobile telecommunications}

There are several possible sources of network effects in mobile telecommunications. First, consider a "traditional", direct effect, like in fixed-line telecommunications. Consumers value the installed base of subscribers, because they can satisfy more communication needs. Since installed base of fixed-line subscribers had been already huge when mobile service emerged and mobile customers can call the stationary numbers, it is not clear whether significant network effects arise because of an additional telephone service, which mobile telecommunications offer. However, short message service (SMS) - available only within mobile network - might help to generate the "traditional" network effects.

\footnotetext{
${ }^{3}$ This was shown by Cabral (1990).
} 
A second possible source of network effects is a need of people to buy, consume, and behave like their fellows, which induces bandwagon effect as in Leibenstein (1950). Economic consequences of this desire to join the crowd, which stems from social interactions were also studied in more recent economic literature (e.g. Granovetter and Soong, 1986; Becker, 1991; Lindbeck et al.,1999; Schoder, 2000). We expect that consumption of mobile telephone service is influenced to some extend by such conformist behavior since mobile telecommunications are clearly important media of social interactions.

Intra-network call discounts offer another explanation for network effects in mobile telecommunications. The reason is very intuitive. Assume that customers apply a balanced calling pattern, which means that the number of calls terminating in each network is proportional to their relative size. Since - because of the discounts - intra-network calls are cheaper than inter-network calls, larger installed base of subscribers to a given provider implies ceteris paribus lower monthly bill for them. The resulting effect is called endogenous network externality in Blonski (2002). We could extend this argument incorporating fixedline network into the analysis. Given, that it is cheaper to call a mobile number from mobile network than from stationary network, larger mobile network implies - as before - lower monthly bill, hence higher attractiveness of mobile telephone service in general. By considering different reference network than Blonski (2002), we obtain network effects operating at industry level and not at firm level, as originally.

We might also expect that quality of mobile telephone service is a priori unknown to consumers. They could learn about the quality from other consumers, who have already subscribed for the service. The installed base of customers would then transmit information to unattached consumers influencing their willingness to pay. Network effects arise in this case, either if the chance of receiving information increases with the size of installed base, or if the network size carries a quality signal.

Additional knowledge about the nature of network effects gives us the extent of compatibility among competing networks, i.e. the level at which the effects operate. The two polar cases are firm-specific network effects on the one hand and industry-specific network effects on the other hand. They correspond to full incompatibility and full compatibility respectively. We could expect the "traditional" effects to be industry specific. The effects raised by information transmission are rather firm specific. Whether the endogenous effects are firm or industry specific or both depends on relative prices of mobile intra-network calls, mobile inter-network calls, and fixed-line to mobile calls. The social interaction concept could support both types of network effects, depending on consumers' reference group. 


\section{Description of the market and related research}

Our empirical investigation regards the second-generation mobile telephone industry that was launched in September 1996 in Poland. The Ministry of Telecommunications (MT) regulator of that industry - granted initially two licenses for providing the mobile telephone service based on GSM 900 standard. To further intensify competition in the industry, the MT offered a GSM 1800 license to a third provider, which started activity in March 1998. The difference between the two standards - GSM 900 and GSM 1800 - is that the latter operates at a higher frequency allowing providers to serve more connections per unit of area at the same time. GSM 1800 is also more costly to install than GSM 900, since it requires higher density of cellular antenna sites. In practice, because of relatively low density of population in Poland, the service based on GSM 1800 standard was offered exclusively in large cities. The entrant became a countrywide provider in March 2000 only after being granted additionally GSM 900 license. Soon after that, the two incumbents obtained GSM 1800 licenses, and started to offer double-frequency service as well. Licensing remained the only way of regulating the industry.

GSM telecommunications turned out to be very successful in Poland unlike its predecessor based on analog technology standard NMT 450i. The analog service - called also the first-generation mobile telecommunications - was introduce in 1992 and reached the size of around 200 thousand subscribers at the time the second-generation service was introduced in 1996. In contrast, four years after the industry launching the total number of GSM subscribers amounted to over 3 million and after the next two years it approached 10 million, roughly $25 \%$ of the total population. Obviously, there are differences in the quality between the analogue NMT and the digital GSM standards, but the extreme market outcomes in terms of network size might indicate presence of network effects.

Demand for mobile telephone service is also likely to be shaped by switching costs. In fact, lack of number portability and long-term contracts, which included a penalty for premature cancellation - a common practice during the period studied - contributed to these costs substantially. The rationale behind keeping high switching costs is twofold. First, they might enable providers to encourage subscriptions by crediting the handsets, which are necessary for using the mobile telephone service. Second, they might strategically weaken price competition by decreasing cross-price elasticity of demand. ${ }^{4}$ In an extreme case with switching costs high enough, providers compete for the unattached consumers only. Our

\footnotetext{
${ }^{4}$ This result is discussed in Beggs and Klemperer (1992) and Klemperer (1995).
} 
empirical framework allows us to account for switching costs to some extent. In particular, it follows from our economic model that the entrants will never catch up with the incumbents in terms of the number of subscribers when switching costs are significant. The unwilling-toswitch installed base of incumbents will cause persistent asymmetry. Testing size of the asymmetry empirically is an indirect way to test the significance of switching costs.

Another important feature of emerging mobile telephone industry is rapidly growing coverage, which determines availability and quality of the service. Clearly, it is not reasonable to subscribe to a mobile network unless it covers one's place of residence. Coverage adds also to the quality of the service, since subscribers can use it while traveling. Data on diffusion of the coverage in the Polish mobile telecommunications we have is not detailed enough to use it explicitly in our analysis. However, general facts, which we observe facilitate to some extent assumptions of our model. First, the coverage grew way faster than the installed base of subscribers. Already one year after GSM telecommunications industry had been launched, the coverage reached $60 \%$ of the total population, while subscribers amounted just to $1,3 \%$. After two years, the corresponding numbers were $80 \%$ and $3 \%$. Second, coverage growth across providers followed basically the same pattern. By ignoring coverage in our analysis, we implicitly assume that the availability constraint does not bind and that consumers do not realize the quality differences among providers due to coverage.

Empirical literature on mobile telecommunications concentrates on determinants of growth and competitiveness of the industry neglecting in general network effects. In the context of fixed-line telecommunications, the study by Bousquet and Ivaldi (1997) is probably the first one, which tests empirically for existence of network effects. In contrast to our study, which focuses on access to telephone service, they concentrate on usage, which seems more relevant in a saturated market that they consider. Consequently, the concept of network externality they use relies on received calls, which benefit subscribers without paying for them, rather than on installed base of subscribers. Next, Okada and Hatta (1999) specify demand for fixed-line and mobile telephone service adopting an Almost Ideal Demand System. They show that the number of mobile subscribers, as a quality measure for telephone service, has significant positive effect on share of telecommunications' expenditures - both mobile and fixed-line - in households' budgets. This result is an empirical evidence for network effects in demand for telephone service. More recently, Kim and Kwon (2003) conduct a conditional logit analysis based on a consumer survey. The analysis reveals that consumers prefer mobile service providers with larger number of subscribers other things being equal. The authors attribute this size effect, which is in line with network effects 
operating at the firm level we found, to intra-network call discounts and quality signaling effect. Finally, Gruber and Verboven (2001) aim to identify factors responsible for timing and speed of mobile service adoption diffusion. However, they take the diffusion's S-shape, which in our framework is driven by network effects, as given without explaining it.

\section{A dynamic model of demand for mobile telephone service: specification and identification}

In order to estimate network effects in demand for mobile telephone service, we focus on access to rather than on usage of the service. Rapidly growing installed base of subscribers to mobile networks justifies this approach. One could potentially extend the analysis allowing subscribers to choose usage level as well. However, this would complicate matters a lot without being crucial to the identification of network effects. The remaining part of this section outlines the model, which guides our empirical analysis. It adopts basically the structural econometric model proposed by Grajek (2002).

We assume that there are several mobile telephone networks in a market. Each of them is operated by single provider and associated with a brand denoted by $i=1,2, \ldots, I(t)$. The number of providers/brands $I(t)$ can vary over time. Consumer utility derived from subscribing for the service is assumed to depend on private intrinsic value attached to it and, at the same time, on the size of installed base of subscribers. To facilitate empirical analysis, instantaneous willingness to pay of each consumer is specified by

$$
u\left(v, x_{i}(t-\delta)\right)=v+c x_{i}(t-\delta)+d x_{i}^{2}(t-\delta),
$$

where consumer type $v$ represents his/her private valuation of the service, $x_{i}(t-\delta)$ denotes the lagged network size of brand $i$, and $c$ and $d$ are parameters determining the extent of network effects. Since $v$ is brand independent, consumers have no taste for a particular brand. We assume that $v$ is uniformly distributed over $(-\infty, a]$ with some density $b>0 .{ }^{5}$ We could equally well introduce a lower bound of the distribution support to limit the population of consumers. We do not do it to avoid the necessity of considering corner solutions, when all consumers subscribe. It is also important to note that network size of brand $i$ is not necessarily equal to its number of subscribers, as it depends on compatibility of networks. Here, compatibility is meant as a measure, which says to what extent subscribers to a given brand value the installed base of other brands. To avoid confusion, we stress that compatibility is not simply implied by interconnection of brands. It depends crucially on the nature of network effects at work, as

\footnotetext{
${ }^{5}$ Here, we do not mean a probability distribution, so the integral over the support of density function does not need to equal 1. In fact, the integral equals $\infty$, when the lower bound of the support equals $-\infty$, which means that there is infinite number of consumers in the market.
} 
it has been discussed in section 2. The relationship between network of a brand and its number of subscribers is expressed by

$$
x_{i}(t)=y_{i}(t)+w y_{-i}(t),
$$

where $y_{i}(t)$ denotes number of subscribers to brand $i$ at time $t, y_{-i}(t)=\sum_{j \neq i} y_{j}(t)$, and $w \in[0,1]$ denotes compatibility among brands. $w=1$ and $w=0$ correspond to the perfect compatibility and perfect incompatibility respectively and the interior values of $w$ indicate a partial compatibility. For simplicity, the compatibility is denoted by a constant in (2), but it is straightforward to condition it on time and/or brand. Actually, we do it at the end of this section to account for changes in intra-network discounts offered by the providers.

Since the focus of this paper is identification of network effects, we do not explicitly model supply side of the market. However, in order to make our demand analysis tractable, we need to restrict pricing behavior of the providers. In particular, we assume that competition in the mobile telephone industry results in setting equal hedonic prices across brands over time. ${ }^{6}$ This assumption seems natural, as consumers' preferences are not brand specific. As a consequence, in each instance of time consumers are indifferent toward brands. Therefore, they do not need to consider potentially costly switching among mobile service providers. Another assumption we make is that providers can credibly commit not to raise their prices. ${ }^{7}$ This assures that mobile service users do never tempt to relinquish subscription. Frequent relinquishing and reopening of subscription might add substantial costs that we do not model in the consumer decision-making.

If consumers correctly foresee that prices will not rise and that competing brands will be equally attractive, their decision to subscribe or not will be fairly simple. They will subscribe when their private valuation of the service exceeds its current hedonic price. In order to determine the number of subscribers, we first calculate the types of indifferent consumers with respect to each brand $i$ from

$$
u\left(v_{i, t}^{*}, x_{i}(t-\delta)\right)=p_{i}(t),
$$

where $p_{i}(t)$ stands for the price of brand $i$ at time $t$. Assumption of equal hedonic prices assures that the types of indifferent consumers $v_{i, t} *$ are equal across the brands. All highertype consumers than $v_{i, t}{ }^{*}$ subscribe to the service - or continue subscription - at time $t$. As a tie-breaking rule, we assume that they choose among the brands with equal probability. Given

\footnotetext{
${ }^{6}$ We use the term hedonic price to depict price corrected for network effects analogously to price corrected for quality, in which context the term hedonic price is usually used.

${ }^{7}$ The option to cancel subscription free of charge in case of an price increase might be a commitment device.
} 
willingness-to-pay function (1) and the assumed uniform distribution of types, the total demand for mobile telephone service at time $t$ is then given by ${ }^{8}$

$$
\sum_{i} y_{i}(t)=a b-b p_{i}(t)+b c x_{i}(t-\delta)+b d x_{i}^{2}(t-\delta) .
$$

In case all providers start their activity simultaneously, our model predicts that they will have equal market shares, so the number of subscribers to each brand $i$ is obtained dividing the RHS of (4) by the number of brands. However, entry might break this symmetry given that significant switching costs are present. In general, we can write the demand for single brand at time $t$ as

$$
y_{i}(t)=l_{i} E(t)+\frac{1}{I(t)}\left(a b-b p_{i}(t)+b c x_{i}(t-\delta)+b d x_{i}^{2}(t-\delta)\right),
$$

where $l_{i}$ are firm specific constants, $E(t)$ is a dummy variable, which is equal to zero in the periods prior to entry and one otherwise, and $I(t)$ equals the number of providers in the market at time $t$. The actual values of $l_{i}$ can be calculated from the size of incumbents' installed base in the entry period. Under switching costs incumbents have an advantage over entrants, which is embodied in positive values of $l_{i}$ for the former and negative $l_{i}$ for the latter. Under no switching costs, $l_{i}$ equals zero for each provider. In any case, the sum of the firm specific constants equals zero, so (4) still holds. ${ }^{9}$

Finally, to obtain equation, which we are going to estimate, we put (2) into (5), then we take a discrete analog of the resulting expression, and we add an error term. This yields

$$
y_{i, t}=\lambda_{i} E_{t}+\frac{1}{I_{t}}\left(\alpha+\beta p_{i, t}+\gamma_{1} y_{i, t-1}+\gamma_{2} y_{i, t-1}^{2}+\gamma_{11} y_{-i, t-1}+\gamma_{21} y_{i, t-1} y_{-i, t-1}+\gamma_{22} y_{-i, t-1}^{2}\right)+\psi_{i, t} .
$$

Possible sources of the error term $\psi_{i, t}$ and its properties will be discussed together with estimation issues in the next section. Once we correctly estimate (6), all structural parameters of the model are identified. Simple algebra yields the highest consumer type in the population $a=-\alpha / \beta$ and density of the distribution of types $b=-\beta$. We can interpret also the parameter $\alpha=a b$ as the number of consumers in the population with positive valuation of the mobile telephone service given zero network size. Network effects parameters $c$ and $d$ can be obtained as $-\gamma_{1} / \beta$ and $-\gamma_{2} / \beta$ respectively. The compatibility parameter $w$ is overidentified, since it can be recovered as $\gamma_{11} / \gamma_{1}$, as $\gamma_{21} / 2 \gamma_{2}$, and as $\pm \sqrt{\gamma_{22} / \gamma_{2}}$. It follows that when the externality operates at the firm level only (incompatible networks, $w=0$ ) we expect the estimates of $\gamma_{11}, \gamma_{21}$ and $\gamma_{22}$ to be zero. In the polar case, when the externality operates at the industry level (fully compatible networks, $w=1$ ), we expect $\gamma_{11}=\gamma_{1}, \gamma_{22}=\gamma_{2}$ and $\gamma_{21}=2 \gamma_{2}$. All

\footnotetext{
${ }^{8}$ For details of the derivation see Grajek (2002).

${ }^{9}$ Ibid.
} 
the intermediate cases with partial compatibility can be easily obtained from the three equalities as well.

The overidentification of the compatibility parameter $w$ gives a scope for a specification test. All three equations identifying $w$ must hold, otherwise either the estimates are not correct, or the data reject the structure. Alternatively, in order to gain in efficiency of estimators, we might identify $w$ from just one relation and build parameter restrictions from the other two.

We could also allow $w$ to vary over time. This might be important in the Polish mobile telephone industry, since providers changed their pricing strategy in the period studied. Initially, the incumbents favored their own subscribers including intra-network call discounts in price schedules. We call it discriminatory pricing, as opposed to non-discriminatory pricing, which does not involve intra-network discounts. The entrant used non-discriminatory pricing from the very beginning and one of the incumbents switched from discriminatory to non-discriminatory regime after the entrant took off. According to endogenous network effects hypothesis described in section 2, this could increase compatibility of mobile telephone networks. To capture this effect we introduce intersections of the regression

variables $\frac{y_{-i, t-1}}{I_{t}}, \frac{y_{i, t-1} y_{-i, t-1}}{I_{t}}$, and $\frac{y_{-i, t-1}^{2}}{I_{t}}$ with firm-specific pricing dummies $D_{i, t}$ into (6). The pricing dummies $D_{i, t}$ take value of zero in the periods prior to introduction of the "nondiscriminatory" pricing by $i$-th provider and one otherwise. The change in compatibility of networks, denoted by $\Delta w$, could be identified from estimates of coefficients on the new intersection variables. The identification of $\Delta w$ is analogous to that of $w$.

\section{Data and Estimation}

The firm-level, quarterly panel data used in this study covers prices and number of subscribers in the Polish mobile telephone industry over 1996-2001. The information on prices has been obtained from the Polish Ministry of Telecommunication (MT). It includes all price plans of each provider. In the period studied, all providers used non-linear pricing in the form of multiple price plans, from which the customers self-select the most favorable one. A plan consists of a monthly fixed charge, a price per minute of usage and often includes some minutes free of charge. A usage price is further diversified according to the time of the day (peak/off-peak hours) and to the termination network (intra-network discounts). Following Parker and Röller (1997), we define the price of a single mobile subscriber as the best-deal monthly bill paid for a given constant calling pattern. That is, we assume some calling pattern 
(including the overall monthly usage and the proportions of the calls in various times of the day and to various networks) and calculate the monthly bills for all available price plans of each provider. ${ }^{10}$ The single price of each provider is then his lowest bill that reflects the bestdeal selection of an average customer. Figure 1 shows nominal prices of each provider over the period studied. We display nominal prices instead of real ones, which we used for estimation, to highlight their particular rigidity. ${ }^{11}$ Over the first three years, the incumbents kept basically constant prices. This situation changed first at the end of 1999 when the entrant was additionally granted GSM 900 license, which enabled him/her to offer a countrywide service.

Unfortunately, the MT did not collect data on the number of subscribers in the mobile telephone industry. Therefore, we utilize the numbers, which had been self-reported by the providers in their yearly reports and press announcements. As figure 2 shows, these numbers were not appearing very regularly, however, they still cover approximately $75 \%$ of the quarterly series for each operator. ${ }^{12}$ Additionally, there are some monthly observations, which fall inside quarters. To fill the remaining $25 \%$ of the quarterly series and still use additional information from the monthly observations we fit a high-degree polynomial time trend to the monthly series and replace missing observations with the fitted trend.

Before we start the estimation stage, there are two more issues, which have to be addressed. First, since we do not account for simultaneous price setting relation and estimate demand relation alone, a potential endogeneity problem arises. However, we claim that the problem might be ignored, since in our economic framework, prices are not likely to response to short-term dynamics in installed base. Optimal dynamic pricing of a telephone service like the one studied here, might involve raising price together with the installed base expansion. ${ }^{13}$ This result is very intuitive, since low initial prices feed the diffusion of networks. However, in the competitive environment we consider, unilateral price increase over the common hedonic price level implies heavy reduction in market share of a given brand. Its provider, would not only attract no new subscribers, but could also loose the installed base if switching costs are low enough. In fact, in case of a price increase, subscribers have the option to quit long-term contract free of charge, which lowers switching costs. Therefore, the feasible dynamic price strategy is likely to involve fixed price over time rather than to react to shortterm dynamics in installed base of subscribers. Figure 1, which plots the prices in the Polish

\footnotetext{
${ }^{10}$ We apply a calling pattern from the OECD Telecommunications Basket Definitions (2000).

${ }^{11}$ Because inflation in the late 90's was still relatively high in Poland (on average 10\% per annum over 19962001), the real prices fall much faster than the nominal once.

${ }_{12}$ By a quarterly observation we mean the number of subscribers at the end of a quarter.

${ }^{13}$ This result is obtained e.g. in Rohlfs (1974) and in Dhebar and Ohren (1985).
} 
mobile telephone industry, supports our claim. Over the first three years, the prices were basically constant, while the total number of subscribers reached almost 3 million. Price cuts in the industry started first with the prospect of new entry into the countrywide service market. ${ }^{14}$ Nevertheless, to account for possible endogeneity of price we adopt instrumental variable technique using lagged values of price as an instrument. This does not change the results in any important way.

The second issue is error structure of the model. So far, we have not assessed the properties of $\psi_{i, t}$ in (6). A common assumption facilitating stochastic components in econometric models is that the researcher knows less about the economic environment than the economic agents. ${ }^{15}$ This might be the case, if dependent variable would be influenced by unobserved factors, which the researcher can only include in an error term. Therefore, this assumption might facilitate an additive error, properties of which depend on the nature of the unobserved factors. Potentially, they could be persistent, common for the whole market and depend on its size. This would imply an autocorrelated, correlated across equations and heteroscedastic error term respectively. Another possibility is that the variables the researcher observes differ from those the agents observe because of data reporting errors. This is likely to be the case with our data. As explained before, we needed to fill the missing values in dependent variable with interpolated ones in order to obtain a balanced panel. Such measurement error in the dependent variable will much more complicate the error structure in (6) than the unobserved factors, because of lagged dependent variables and their squares included as regressors there. For instance, if we assume, that the stochastic noise in the model is just due to an additive i.i.d. measurement error $\varepsilon_{i, t}$ in dependent variable, then the process generating the error term in (6) will be a nonlinear function of the measurement error, the dependent variable, and parameters of the model. To save on complicated notation, one could write it as

$$
\psi_{i, t}=\varepsilon_{i, t}+g\left(I_{t}, y_{i, t-1}, y_{-i, t-1}, \varepsilon_{i, t-1}, \varepsilon_{-i, t-1} ; \theta\right)
$$

where $\theta=\left(\gamma_{1}, \gamma_{2}, \gamma_{11}, \gamma_{12}, \gamma_{22}\right)$ and $g($.$) is known. The system (6)+(7)$ has features of a multivariate bilinear model studied in time series literature.

We consider two estimation techniques in this paper. The first is generalized method of moments (GMM), which is attractive, because it does not restrict the error covariance matrix. In particular, it allows the error term in our model to be driven by the unobserved factors or

\footnotetext{
${ }^{14}$ Since the number of licenses for the mobile telephone service is regulated in Poland, we treat entry as an exogenous event.

${ }^{15}$ See the discussion about introducing stochastic components into a deterministic economic model in Reiss and Wolak (2002).
} 
the measurement errors, both of which can be heteroscedastic, autocorrelated and correlated across equations. The issue here, however, is a proper set of instruments. Since, we do not have better ones than lagged values of the variables in the model, the usefulness of GMM is limited. The problem is that autocorrelated errors in models involving lagged dependent variable might invalidate any further lags of the dependent variable as instruments. In particular, we will not be able to correctly estimate (6) by GMM, when the errors follow an autoregressive process. Another problem is small size of our sample, which might call for a more restricted error structure in order to gain in efficiency of estimates.

To account for these problems, we consider another technique, which Hannan and Rissanen (1982; HR thereafter) proposed for estimating linear ARMA models. Granger and Teräsvirta (1993, p.125) advocate this technique, as relatively simplest, for estimating bilinear models. For the system (6) + (7), it proceeds as follows. In the first step, we estimate (6) by OLS. Then, we insert the lagged OLS residuals into (7) as proxies for the lagged measurement error's realizations and estimate the model substituting (7) into (6). The new least squares residuals (lagged) are inserted as new proxies into (7) and the model is reestimated. ${ }^{16}$ The iteration is continued to convergence, which means stabilization of residual variance. The HR technique allows us to take complex error structures that might stem from our assumptions explicitly into account. In principal, we could test validity of the assumed error structure by testing estimated coefficients in (7) against their theoretical values $\theta$. Because of the small size of our sample relative to the number of coefficients in (6), we restrict them however to equal $\theta$.

\section{Interpretation of the empirical results}

Table 1 shows the estimation results of equation (6). Structural parameters of our economic model identified from the estimated coefficients can be found in table 2 . We estimate six regressions, which differ in terms of estimation technique, parameter restrictions and error structure. Column labels in both tables identify the regressions. As mentioned before, our economic structure allows us to introduce some parameter restrictions into the model (6). Indeed, we restrict two out of three coefficients in both "Cross-network effects" group and "Pricing regime" group of table 1 using overidentification of the compatibility parameters $w$ and $\Delta w$. In particular, the coefficients on $y_{i, t-1} y_{j, t-1}$ and $y_{j, t-1}^{2}$ were set as $\gamma_{21}=$ $2 \gamma_{11} \gamma_{2} / \gamma_{1}$ and $\gamma_{22}=\left(\gamma_{11} / \gamma_{1}\right)^{2} \gamma_{2}$ respectively. The coefficients on $D_{i} y_{i, t-1} y_{j, t-1}$ and $D_{i} y_{j, t-1}^{2}$ were set

\footnotetext{
${ }^{16}$ Since each iteration involves the use of lagged residuals from the previous estimation, we would loose observations each time. To avoid this problem, we set the missing (first) lagged residual to zero.
} 
analogously. In some regressions, we restrict also the "Fixed effects of entry". Their theoretical values could be calculated from the data without estimation. ${ }^{17}$ We would expect them to be zero, if switching costs in the industry were negligible. In the case of significant switching costs, we would expect $\lambda_{1}$ and $\lambda_{2}$ to equal 1,3 and $\lambda_{3}$ to equal $-2,6$. These numbers mean that persistent advantage of each incumbent over entrant in terms of installed base would amount to 390 thousand subscribers.

The results in the first two columns of table 1 are obtained by applying iterated GMM estimation. Regression (a) is a benchmark, where it is assumed that there are no network effects in demand for the mobile telephone service. In this case, our economic structure boils down to a basic linear demand model. For consistency with the remaining five regressions, the benchmark regression (a) is estimated on data aggregated to the industry level. Lagged aggregated price and a constant were used as instruments. With this set of instruments the regression coefficients are exactly identified, i.e. there are no over-identifying moment conditions.

Column (b) of table 1 shows the iterated GMM estimates of the full model's coefficients. As instruments served lagged by two periods number of subscribers, lagged prices - both subscribers and prices at the firm level - and a constant. The over-identifying moment conditions seem valid. The value of the Wald statistics 7,15 falls under the $5 \%$ critical value 21,03 . The estimated coefficients in the regression (b) are in general highly significant and they have expected signs. The price effect is drastically smaller than that in the benchmark regression. Instead, there is an evidence for positive network effects in the regression (b). As table 2 reports, the identified network effects parameters $c$ and $d$ are equal 227,7 and $-0,7$ respectively. These results imply that the marginal network effects are downward sloping, as it is commonly assumed in the theoretical literature. Compatibility in the Polish mobile telephone market is low, although statistically very significant. The estimate of $w$ equals 0,063 , which means that the subscribers value own-brand installed base 16 times more than the installed base of other brands. Abandoning of intra-network discounts slightly increases the compatibility, as indicated by the parameter $\Delta w$ in table 2.

The only insignificant coefficients in regression (b) are the incumbents' fixed effects of entry $\lambda_{1}$ and $\lambda_{2}$. The entrant's fixed effect $\lambda_{3}$ is negative, but relatively small. As mentioned before, we expect that each incumbent's advantage over entrant amounts roughly to 400 thousand subscribers, when switching costs are significant in the industry. The estimated

\footnotetext{
${ }^{17}$ For details concerning derivation of fixed effects of entry in our economic model we use see Grajek (2002).
} 
fixed effects in (b) tell us that the advantage equals just 60 thousand, which suggests that the switching costs are in fact low. ${ }^{18}$

As we mentioned in the previous section, the presence of autocorrelation invalidates the GMM estimates in our case. The pooled Durbin-Watson statistic in regression (b) falls into inconclusive region giving no clear indication of autocorrelation. ${ }^{19}$ To check robustness of the GMM estimation results, we proceed imposing more structure on the error term and applying the estimation technique devised by HR. First, we assume that the stochastic noise in the model (6) is due to an additive i.i.d. measurement error $\varepsilon_{i, t}$ in dependent variable. ${ }^{20}$ Then, the error term $\psi_{i, t}$ in (6) can be represented by (7). Column (c) in table 1 reports estimation results of the model (6) $+(7)$. The coefficients in the regression (c) are not highly significant and the pooled Durbin-Watson statistic indicates autocorrelation. ${ }^{21}$

To improve statistical properties of the model we restrict fixed effects of entry in accordance with our economic structure. Point estimates of the fixed effects of entry in regression (c) suggest that the number of subscribers of the entrant and of the incumbents differ substantially. The magnitude of this difference, which equals roughly 3.9 , is in line with the predictions of our economic model given that there are significant switching costs in the industry. However, in comparison with theoretical predictions, the values of all three parameters $\lambda_{\mathrm{i}}$ are shifted down by 1.3. Given relatively low statistical significance of the coefficients in regression (c), this downward shift might be due to difficulties with disentangling the common intercept from fixed effects of entry by the estimation procedure. Therefore, we restrict the coefficients of the fixed effects of entry to their theoretical values. The statistical significance of the estimated coefficients improves, as we see in column (d) of table 1. However, the pooled Durbin-Watson statistic still indicates autocorrelation of the error term, which we interpret as an evidence for misspecification of the model. ${ }^{22}$

\footnotetext{
${ }^{18}$ Precisely speaking, our economic structure does not support any intermediate values of fixed effects of entry between those implied by insignificant and significant switching costs. However, the intermediate values intuitively imply a gradual catching up of entrant in terms of number of subscribers. This would happen, if switching costs are in some sense low.

${ }^{19}$ Formally, the Durbin-Watson statistic, which we report in table 1, is not an appropriate test in presence of lagged dependent variables, because it is usually biased toward a finding of no autocorrelation.

${ }^{20}$ We also tried to estimate the model assuming that the error term in (6) is driven by unobserved factors that are autocorrelated. To account for the autocorrelated error term in presence of lagged dependent variables, we applied approach devised by Hatanaka (1974), which is based on instrumental variable technique. The results were not satisfactory. In particular, the basic demand coefficients were not statistically significant.

${ }^{21}$ To account for possible endogeneity of price, we also estimated (c) replacing least squares with instrumental variable technique at each iteration of the HR procedure. As an instrument for price we took its lagged value. The procedure did not converge. Applying the same modification to regressions (d) - (f) we obtained convergence, but the estimates were only slightly changed, so we do not report these results.

${ }^{22}$ Another problem with regressions (c) and (d) was convergence of the estimation procedure. Each of them converges to two distinct solutions. Since in each case the solutions are very close to each other, we report just one of them.
} 
To account for the autocorrelated disturbances $\varepsilon_{i, t}$ in the model (6) $+(7)$ we include lagged residuals of the model as an additional regressor in (6). Columns (e) and (f) in table 1 show the results of this exercise without and with restrictions on estimated fixed effects of entry respectively. Both regressions display now good statistical properties. In particular, the pooled Durbin-Watson statistic no longer indicates autocorrelation of the error term. To ensure that the finding of no autocorrelation is correct, we conduct a modification of BreuschGoldfrey test consisting of regressing residuals from each of the regressions (e) and (f) on their full set of regressors plus lagged residuals and testing significance of coefficients on the lagged residuals. Each time we use one, two and four lags and test their joint significance with the standard $F$ test. In none of the cases we could reject the null hypothesis of no autocorrelation. Although, the regressions (e) and (f) perform well in statistical terms, they differ substantially in their economic relevance. All the variation of the dependent variable in regression (e) is explained by autoregressive factors leaving coefficients on basic demand variables insignificant and with wrong signs. In contrast, regression (f) performs well, both in statistical and economic terms, providing a useful robustness check for the GMM estimates in regression (b). ${ }^{23}$

In general, the results of regressions (f) confirm those of regression (b) in the way both sets of results differ from the benchmark. The price coefficient in column (f) of table 1, which equals $-0,057$, is smaller than in the benchmark regression (a) by an order of magnitude. The marginal network effects are positive ${ }^{24}$ and diminishing, as indicated by parameters $c$ and $d$ in column (f) of table 2. Also, the estimated compatibility measure $w$, which equals 0,089 , is relatively low. However, the difference in magnitude of price and network effects between regressions (b) and (f) gives rise to very diverted predictions concerning demand in the Polish mobile telephone industry. To see it, we plot steady-state demand in the industry, which is derived from (6) given that $y_{i}=y_{i-1}$ for all $i$. On the horizontal axis of figure 3 , there is aggregated number of subscribers in the industry $y=\sum_{i} y_{i}$. For simplicity of the exposition we assume that there are three providers of equal size in the market, hence the prices across providers are also equal and are represented by a common price $p$. As a reference, we include also demand function implied by the benchmark regression (a) in figure 3. We see that the estimated network effects in regressions (b) and (f) give rise to upward-sloping parts in the

\footnotetext{
${ }^{23} \mathrm{We}$ also tried to restrict the fixed effects of entry in regression (e) to zero. The HR estimation procedure did not converge.

${ }^{24}$ The marginal network effects are positive for a network (and not installed base) smaller than 30,6 mill. subscribers. Since the population of Poland reaches 40 mill., they are positive roughly over the whole relevant range.
} 
inverse steady-state demand functions. As discussed in Grajek (2002), the upward-sloping parts consist of unstable equilibria and correspond to the notion of critical mass. Once the critical mass is reached for a given price $p$, the number of subscribers in the market tends to and eventually reaches the stable steady state on the downward-sloping part of the demand. In the opposite case, the market shrinks to zero. Focusing on the stable steady states, we note that for each price, regression (b) implies higher demand than regression (f), which in turn implies higher demand than the benchmark regression (a). E.g., for $p$ equal 100 zloty, the demand is estimated at roughly 15, 13 and 7 million subscribers by regression (b), (f) and (a) respectively. The same ranking sustains for the price sensitivity of demand, regression (b) supporting the least sensitive one. Converting the estimated coefficients into price elasticities $^{25}$, evaluated at the sample means, we obtain $-0,4,-1,2$, and $-3,0$ for regressions (b), (f) and (a) respectively. In fact, the most important conclusion that we draw from comparison of the three regressions' results is that ignoring network effects leads to significant overestimation of the elasticity. The intuition behind direction of the bias is the following. By ignoring installed base we falsely attribute all changes in current number of subscriptions to changes in price alone. Since both rising installed base of subscribers and falling price lead to more subscriptions, if, loosely speaking, price and installed base are negatively correlated, then the price coefficient is biased downward and consequently the price elasticity overestimated. We formalize this intuition in the Appendix.

Another question of interest is to what extent the identified network effects and compatibility alter demand in the industry. To answer this question we simulate the steadystate demand, implied by the estimates of regression (f), manipulating values of the respective structural parameters. The results of this exercise are illustrated in figure 4 . Note that the demand function under non-discriminatory pricing, in which case compatibility equals $0,089+0,036=0,125$, indicated by a bold solid line in figure 4 , corresponds exactly to the demand function implied by regression (f) in figure 3. Setting the network effect parameters $c$ and $d$ to zero, we obtain linear demand function indicated by a thin solid line in figure 4 . Without network effects, the market size shrinks roughly from 15 to 1 million subscribers. The extent of network effects we found might explain why the second-generation telecommunications in Poland performed so much better than the first generation, as we mentioned in section 3. First, marginal network effects in the analog first generation might diminish much faster than in digital second generation because of congestion effects. Second,

\footnotetext{
${ }^{25}$ In the case of regressions (b) and (f), we mean long-run price elasticity, i.e. we account for the change in demand between two steady states. Obviously, the short-run elasticities are even smaller than the long-run ones reported in the text.
} 
provider of the first generation service might have failed to attract the critical mass of subscribers. To assess the economic significance of compatibility, we additionally plot steady-state demand function under discriminatory pricing, i.e. for $w=0,089$, in figure 4 . Although, the difference in compatibility between the two pricing regimes seems marginal, it produces a noticeable difference in terms of steady-state demand. In particular, difference in the market size amounts to 2 million subscribers. We conclude that compatibility parameters, we identified in the Polish mobile telecommunications, are not only statistically, but also economically significant.

Finally, given the extent of compatibility we found, one could discriminate among possible sources of network effects in mobile telecommunications. As we discussed in section 2, some of them are more likely to generate firm specific effects (low compatibility), while the other industry specific effects (high compatibility). We are also able to test the endogenous network effect hypothesis, as in Blonski (2002), more directly, estimating change in the compatibility due to abandoning of intra-network discounts. Our results provide an empirical evidence in favor of the endogenous network effect hypothesis, since $\Delta w$ is both statistically and economically significant. However, this hypothesis alone is not able to explain the network effects we observe. Even under non-discriminatory pricing, compatibility in the industry remains low. This suggests that the network effects in mobile telecommunications might also be raised by transmission of information about quality of the service and Leibenstein's (1950) conformist behavior of consumers.

\section{Conclusions}

In this paper we specify and estimate a structural model of demand for mobile telephone service. The focus of the study is to provide empirical evidence concerning the extent of network effects and compatibility in mobile telecommunications. The structural approach we follow allows us to identify the parameters of interest from the S-shape of mobile service diffusion. Data for the analysis come from the Polish mobile telephone industry and cover the period 1996-2001, i.e. from introduction of the second generation digital service till recently.

Our results suggest that there are strong network effects in the Polish mobile telecommunications both in statistical and economic terms. The regression coefficients and the identified structural parameters capturing the extent of the effects are statistically highly significant. To illustrate their economic significance, we derive steady-state demand in the industry and compare it to the simulated demand without network effects. The market size 
that results from setting network effects to zero is 15 times smaller than in the full model. As a benchmark, we also estimate a restricted regression that does not account for network effects. The estimated price elasticity of demand in there is much higher, since we falsely attribute changes in demand due to network effects to changes in price. We formalize this result showing that ignoring network effects in empirical models of emerging network industries can substantially bias downward the estimated elasticity of demand.

We provide also empirical evidence on compatibility of competing networks in mobile telecommunications. In general, we find that the compatibility is low. It amounts to 0,089 under discriminatory pricing, which involves intra-network call discounts. After abandoning of the discounts, the compatibility increases to 0,125 . This seemingly marginal increase leads to expansion of the market size by roughly 2 million subscribers, i.e. $15 \%$. Given the compatibility we found, one could discriminate among possible sources of network effects in mobile telecommunications. The significant implications of intra-network call discounts we report supports endogenous network effects as one of the sources. The endogenous network effects hypothesis states that larger installed base of subscribers to a given brand implies lower monthly bill for them, hence network effects at the firm level, if intra-network calls are cheaper than inter-network ones. Since without such discriminatory pricing, the compatibility is still relatively low, we conclude that endogenous effects alone are not able to explain the network effects we find. Transmission of information about quality of the service and conformist behavior of consumers might offer alternative explanations. 


\section{Appendix}

This section formalizes the intuition behind the direction of bias in the estimated price elasticity of demand when we ignore network effects. Suppose that correctly specified linear demand model reads:

(A.1) $y=X_{1} \beta_{1}+X_{2} \beta_{2}+\varepsilon$,

where $y$ is an $N \times 1$ vector of quantities, $X_{1}$ is an $N \times K$ matrix, columns of which are $N$ observations on each out of $K$ basic explanatory variables and $\beta_{1}$ is a $K \times 1$ vector of corresponding parameters. $X_{2}$ denotes an $N \times L$ matrix of variables responsible for network effects and $\beta_{2}$ is an $L \times 1$ vector of parameters. $\varepsilon$ stands for an $N \times 1$ vector of disturbances and $E[\varepsilon]=0$. We allow for heteroscedasticity and autocorrelation of disturbances letting the covariance matrix $E\left[\varepsilon \varepsilon^{\prime}\right]=\Sigma$. Suppose further that some variables in $X_{1}$ are not orthogonal to $\varepsilon$ and a valid set of instruments for them is included in $Z$, which is an $N \times M$ matrix, and $M \geq K$.

If we regress $y$ on $X_{1}$ without including $X_{2}$ our GMM estimate of $\beta_{1}$ is then:

$$
\begin{aligned}
b_{1}{ }^{\mathrm{GMM}} & =\left[X_{1}{ }^{\prime} Z S^{-1} Z^{\prime} X_{1}{ }^{\prime}\right]^{-1}\left[X_{1}{ }^{\prime} Z S^{-1} Z^{\prime} y\right]= \\
& =\left[X_{1}{ }^{\prime} Z S^{-1} Z^{\prime} X_{1}{ }^{\prime}\right]^{-1}\left[X_{1}{ }^{\prime} Z S^{-1} Z^{\prime}\left(X_{1} \beta_{1}+X_{2} \beta_{2}+\varepsilon\right)\right]= \\
& =\beta_{1}+\left[X_{1}{ }^{\prime} Z S^{-1} Z^{\prime} X_{1}{ }^{\prime}\right]^{-1}\left[X_{1}{ }^{\prime} Z S^{-1} Z^{\prime} X_{2}\right] \beta_{2}+\left[X_{1}{ }^{\prime} Z S^{-1} Z^{\prime} X_{1}{ }^{\prime}\right]^{-1}\left[X_{1}{ }^{\prime} Z S^{-1} Z^{\prime} \varepsilon\right],
\end{aligned}
$$

where $S$ is a matrix from the sample data that converges in probability to the same matrix as $\frac{1}{N} Z^{\prime} \Sigma Z$. In particular, if disturbances $\varepsilon$ are uncorrelated, $S$ could be the White (1980) estimator, otherwise it could be the Newey and West (1987) estimator.

To assess asymptotic properties of the estimator in (A.2) let us first assume that $\frac{1}{N} Z^{\prime} \Sigma Z, \frac{1}{N} X_{1}{ }^{\prime} X_{1}$ and $\frac{1}{N} X_{2}{ }^{\prime} X_{2}$ converge in probability to positively definite matrixes, and that $\frac{1}{N} Z^{\prime} X_{1}$ and $\frac{1}{N} Z^{\prime} X_{2}$ converge in probability to nonzero matrixes. Then:

$$
\begin{aligned}
\operatorname{plim} b_{1}{ }^{\mathrm{GMM}}= & \beta_{1}+\operatorname{plim}\left[\left(\frac{1}{N} X_{1}{ }^{\prime} Z\right) S^{-1}\left(\frac{1}{N} Z^{\prime} X_{1}{ }^{\prime}\right)\right]^{-1}\left[\left(\frac{1}{N} X_{1}{ }^{\prime} Z\right) S^{-1}\left(\frac{1}{N} Z^{\prime} X_{2}\right)\right] \beta_{2}+ \\
& +\operatorname{plim}\left[\left(\frac{1}{N} X_{1}{ }^{\prime} Z\right) S^{-1}\left(\frac{1}{N} Z^{\prime} X_{1}{ }^{\prime}\right)\right]^{-1}\left[\left(\frac{1}{N} X_{1}{ }^{\prime} Z\right) S^{-1}\left(\frac{1}{N} Z^{\prime} \varepsilon\right)\right] .
\end{aligned}
$$

If $Z$ is indeed a proper set of instruments for $X_{1}$ in model (A.1), then $E\left[z_{n} \varepsilon_{n}\right]=0$, where the subscript $n=1,2, \ldots, N$ depicts the $n$-th row of the corresponding matrix, so plim $\frac{1}{N} Z^{\prime} \varepsilon=0$ and the third term on the RHS of (A.3) vanishes. However, the second term on the RHS of (A.3) does not, which means that the estimator is inconsistent. Multiplying out the second 
term on the RHS of (A.3) we obtain a vector of persistent biases. The direction of bias on the price coefficient is of particular interest for us. Suppose for simplicity that $X_{2}$ contains just one variable - the lagged dependent variable, i.e. installed base in our setting - so that $\beta_{2}$ is a scalar. If network effects are positive on average then $\beta_{2}$ will be positive. The vector of biases in (A.3) is then a product of a positive scalar and probability limit of a string of matrix computations, which we recognize as an estimator of some parameter vector $\gamma$ from the following relation:

(A.4) $X_{2}=X_{1} \gamma+v$.

If $Z$ again contains proper set of instruments than the estimator of $\gamma$ is consistent and we can finally state that the direction of bias on the price coefficient in our original demand model ignoring network effects is determined by the sign of parameter on price in (A.4). Negative correlation - negative partial correlation if $X_{1}$ contains more variables than just constant and price - between price and installed base implies then downward bias on price coefficient, hence on price elasticity, in the misspecified demand. This direction of the bias is especially likely in the emerging network markets, where installed base increases and price tends to decrease over time. 
Table 1. Demand in the Polish mobile telephone industry: Estimation results ${ }^{a}$

\begin{tabular}{|c|c|c|c|c|c|c|}
\hline Variables & $(a)^{b}$ & (b) & (c) & (d) & (e) & (f) \\
\hline \multicolumn{7}{|l|}{ Basic demand } \\
\hline Intercept & $\begin{array}{c}143,6^{* * *} \\
(23,2)\end{array}$ & $\begin{array}{c}2,620^{* *} \\
(2,50)\end{array}$ & $\begin{array}{l}13,97^{*} \\
(1,73)\end{array}$ & $\begin{array}{c}12,31^{* * *} \\
(2,89)\end{array}$ & $\begin{array}{l}-4,646 \\
(-1,23)\end{array}$ & $\begin{array}{c}9,340^{* * *} \\
(4,68)\end{array}$ \\
\hline$p_{i, t}$ & $\begin{array}{c}-0,735^{* * * \mathrm{c}} \\
(-16,6)\end{array}$ & $\begin{array}{c}-0,014^{* *} \\
(-2,64)\end{array}$ & $\begin{array}{l}-0,065 \\
(-1,68)\end{array}$ & $\begin{array}{c}-0,072^{* * *} \\
(-3,35)\end{array}$ & $\begin{array}{l}0,022 \\
(1,22)\end{array}$ & $\begin{array}{c}-0,057^{* * *} \\
(-5,62)\end{array}$ \\
\hline \multicolumn{7}{|l|}{ Own network effects } \\
\hline$y_{i, t-1}$ & - & $\begin{array}{c}3,185^{* * *} \\
(37,7)\end{array}$ & $\begin{array}{c}2,756^{* * *} \\
(4,73)\end{array}$ & $\begin{array}{c}2,886^{* * *} \\
(15,7)\end{array}$ & $\begin{array}{c}3,202^{* * *} \\
(14,1)\end{array}$ & $\begin{array}{c}2,850^{* * *} \\
(29,7)\end{array}$ \\
\hline$y_{i, t-1}^{2}$ & - & $\begin{array}{c}-0,010^{* * *} \\
(-6,40)\end{array}$ & $\begin{array}{r}-0,0101^{*} \\
(-1,83)\end{array}$ & $\begin{array}{c}-0,0097^{* *} \\
(-2,42)\end{array}$ & $\begin{array}{c}-0,0055^{* *} \\
(-2,07)\end{array}$ & $\begin{array}{c}-0,0093^{* * *} \\
(-4,36)\end{array}$ \\
\hline \multicolumn{7}{|l|}{ Cross-network effects ${ }^{\mathrm{d}}$} \\
\hline$y_{-i, t-1}$ & - & $\begin{array}{c}0,200^{* * *} \\
(6,87)\end{array}$ & $\begin{array}{l}0,298 \\
(1,66)\end{array}$ & $\begin{array}{l}0,182^{*} \\
(1,95)\end{array}$ & $\begin{array}{l}0,141^{*} \\
(1,97)\end{array}$ & $\begin{array}{c}0,254^{* * *} \\
(5,77)\end{array}$ \\
\hline \multicolumn{7}{|l|}{ Pricing regime ${ }^{\mathrm{d}}$} \\
\hline$D_{i} y_{-i, t-1}$ & - & $\begin{array}{c}0,052^{* *} \\
(2,92)\end{array}$ & $\begin{array}{l}0,064 \\
(0,88)\end{array}$ & $\begin{array}{c}0,141^{* * *} \\
(2,93)\end{array}$ & $\begin{array}{l}-0,012 \\
(-0,40)\end{array}$ & $\begin{array}{c}0,102^{* * *} \\
(4,27)\end{array}$ \\
\hline \multicolumn{7}{|l|}{ Fixed effects of entry } \\
\hline$\lambda_{1}$ & - & $\begin{array}{l}0,167 \\
(0,64)\end{array}$ & $\begin{array}{l}0,614 \\
(0,66)\end{array}$ & 1,3 & $\begin{array}{c}1,421^{* * *} \\
(3,74)\end{array}$ & 1,3 \\
\hline$\lambda_{2}$ & - & $\begin{array}{l}0,183 \\
(1,03)\end{array}$ & $\begin{array}{l}-0,031 \\
(-0,03)\end{array}$ & 1,3 & $\begin{array}{c}1,018^{* * *} \\
(2,77)\end{array}$ & 1,3 \\
\hline$\lambda_{3}$ & - & $\begin{array}{c}-0,766^{* *} \\
(-2,47)\end{array}$ & $\begin{array}{l}-3,949 \\
(-1,65)\end{array}$ & $-2,6$ & $\begin{array}{l}0,786 \\
(0,76)\end{array}$ & $-2,6$ \\
\hline \multicolumn{7}{|l|}{ Lagged disturbances } \\
\hline$\varepsilon_{i, t-1}$ & - & - & - & - & $\begin{array}{c}0,933^{* * *} \\
(5,92)\end{array}$ & $\begin{array}{c}1,164^{* * *} \\
(8,19)\end{array}$ \\
\hline $\mathrm{N}$ & 20 & 54 & 57 & 57 & 57 & 57 \\
\hline pooled D-W & 0,52 & 1,71 & 0,81 & 0,79 & 1,99 & 1,99 \\
\hline
\end{tabular}

\footnotetext{
*** denotes significance at $1 \%$ level, ${ }^{* *}$ at $5 \%$ level, ${ }^{*}$ at $10 \%$ level; $t$-statistics in parentheses.

a (a) and (b) are estimated by iterated GMM, (c) - (f) are estimated by technique devised in Hannan and Rissanen (1982).

${ }^{\mathrm{b}}$ For consistency with the results of other estimations the observations in (a) are aggregated to the market level.

${ }^{\mathrm{c}}$ Aggregated price is calculated as average price across providers weighted by their market shares.

${ }^{\mathrm{d}}$ Restrictions on regression coefficients, which over-identify structural parameters, are imposed.
} 
Table 2. Identified structural parameters of demand in the Polish mobile telephone industry ${ }^{a}$

\begin{tabular}{|c|c|c|c|c|c|}
\hline Parameters & (b) & (c) & (d) & (e) & (f) \\
\hline \multicolumn{6}{|l|}{$\begin{array}{l}\text { Distribution of } \\
\text { consumer types }\end{array}$} \\
\hline$a$ & $\begin{array}{c}187,3^{* * *} \\
(14,7)\end{array}$ & $\begin{array}{c}215,0^{* * *} \\
(17,8)\end{array}$ & $\begin{array}{c}170,6^{* * *} \\
(12,5)\end{array}$ & $\begin{array}{c}209,9^{* * *} \\
(13,1)\end{array}$ & $\begin{array}{c}163,5^{* * *} \\
(17,9)\end{array}$ \\
\hline$b$ & $\begin{array}{c}0,014^{* *} \\
(2,64)\end{array}$ & $\begin{array}{l}0,065 \\
(1,68)\end{array}$ & $\begin{array}{c}0,072^{* * *} \\
(3,35)\end{array}$ & $\begin{array}{l}-0,022 \\
(-1,22)\end{array}$ & $\begin{array}{c}0,057^{* * *} \\
(5,62)\end{array}$ \\
\hline \multicolumn{6}{|l|}{ Network effects } \\
\hline$c$ & $\begin{array}{l}227,7^{* *} \\
(2,67)\end{array}$ & $\begin{array}{l}42,42 \\
(1,33)\end{array}$ & $\begin{array}{c}40,00^{* * *} \\
(3,34)\end{array}$ & $\begin{array}{l}-144,7 \\
(-1,28)\end{array}$ & $\begin{array}{c}49,91^{* * *} \\
(5,59)\end{array}$ \\
\hline$d$ & $\begin{array}{c}-0,706^{* * *} \\
(-3,17)\end{array}$ & $\begin{array}{l}-0,156 \\
(-1,29)\end{array}$ & $\begin{array}{l}-0,135^{*} \\
(-1,94)\end{array}$ & $\begin{array}{l}0,250 \\
(0,98)\end{array}$ & $\begin{array}{c}-0,163^{* * *} \\
(-3,45)\end{array}$ \\
\hline \multicolumn{6}{|l|}{ Compatibility } \\
\hline$w$ & $\begin{array}{c}0,063^{* * *} \\
(6,00)\end{array}$ & $\begin{array}{l}0,108 \\
(1,27)\end{array}$ & $\begin{array}{l}0,063^{*} \\
(1,86)\end{array}$ & $\begin{array}{l}0,044^{*} \\
(1,77)\end{array}$ & $\begin{array}{c}0,089^{* * *} \\
(5,36)\end{array}$ \\
\hline$\Delta w$ & $\begin{array}{c}0,016^{* * *} \\
(3,08)\end{array}$ & $\begin{array}{l}0,023 \\
(0,78)\end{array}$ & $\begin{array}{c}0,049^{* * *} \\
(3,05)\end{array}$ & $\begin{array}{l}-0,004 \\
(-0,40)\end{array}$ & $\begin{array}{c}0,036^{* * *} \\
(4,40)\end{array}$ \\
\hline
\end{tabular}

denotes significance at $1 \%$ level, ${ }^{* *}$ at $5 \%$ level, ${ }^{*}$ at $10 \%$ level; t-statistics in parentheses.

${ }^{\text {a }}$ Column labels correspond to these in table 1. 
Figure 1. Best-deal prices in the Polish mobile telephone industry (in current zloty)*

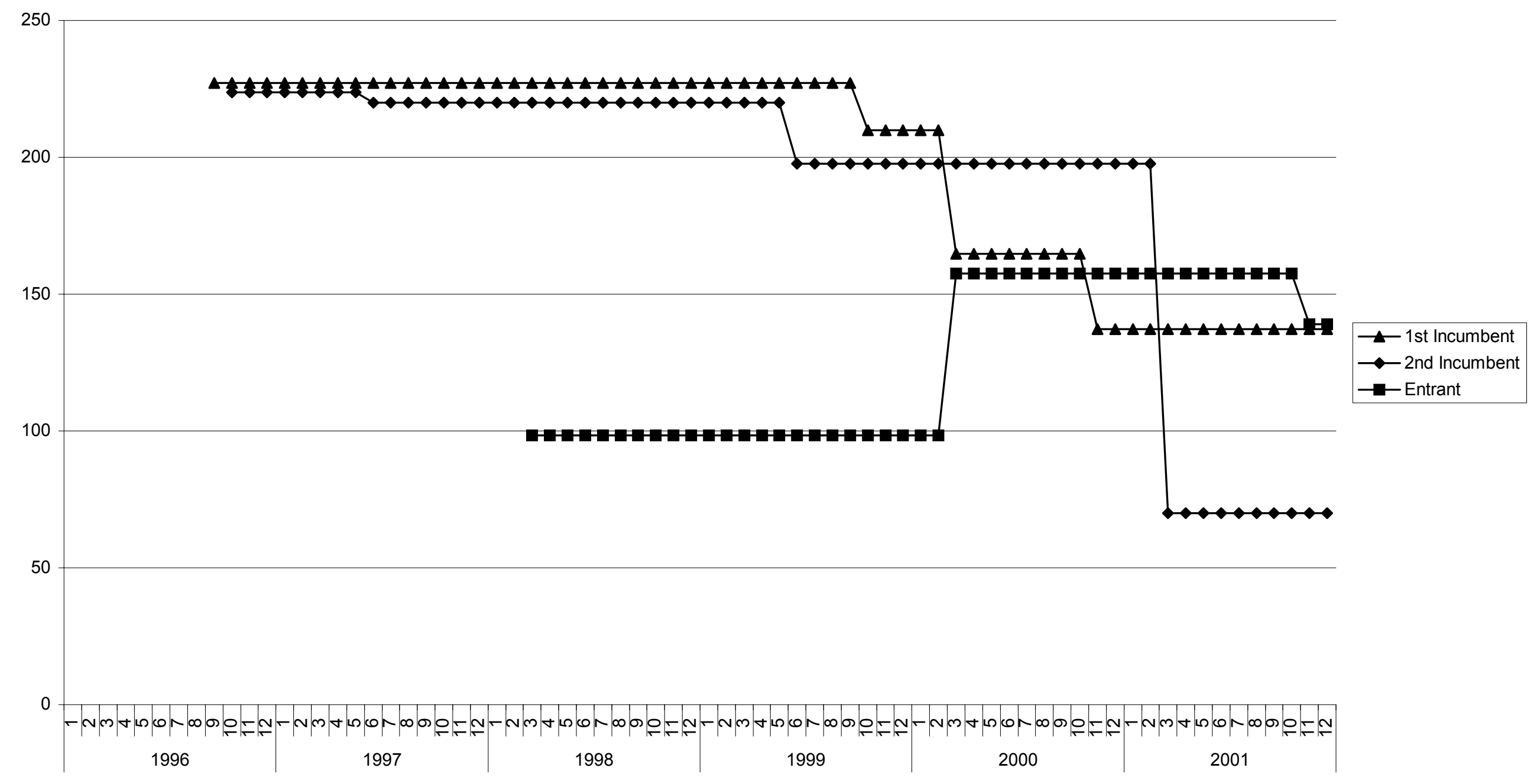

* In the period studied 1 U.S. dollar $\approx 4$ Polish zloty; prices used for estimation are in September 1996 Polish zloty. 
Figure 2. Number of subscribers in the Polish mobile telephone industry

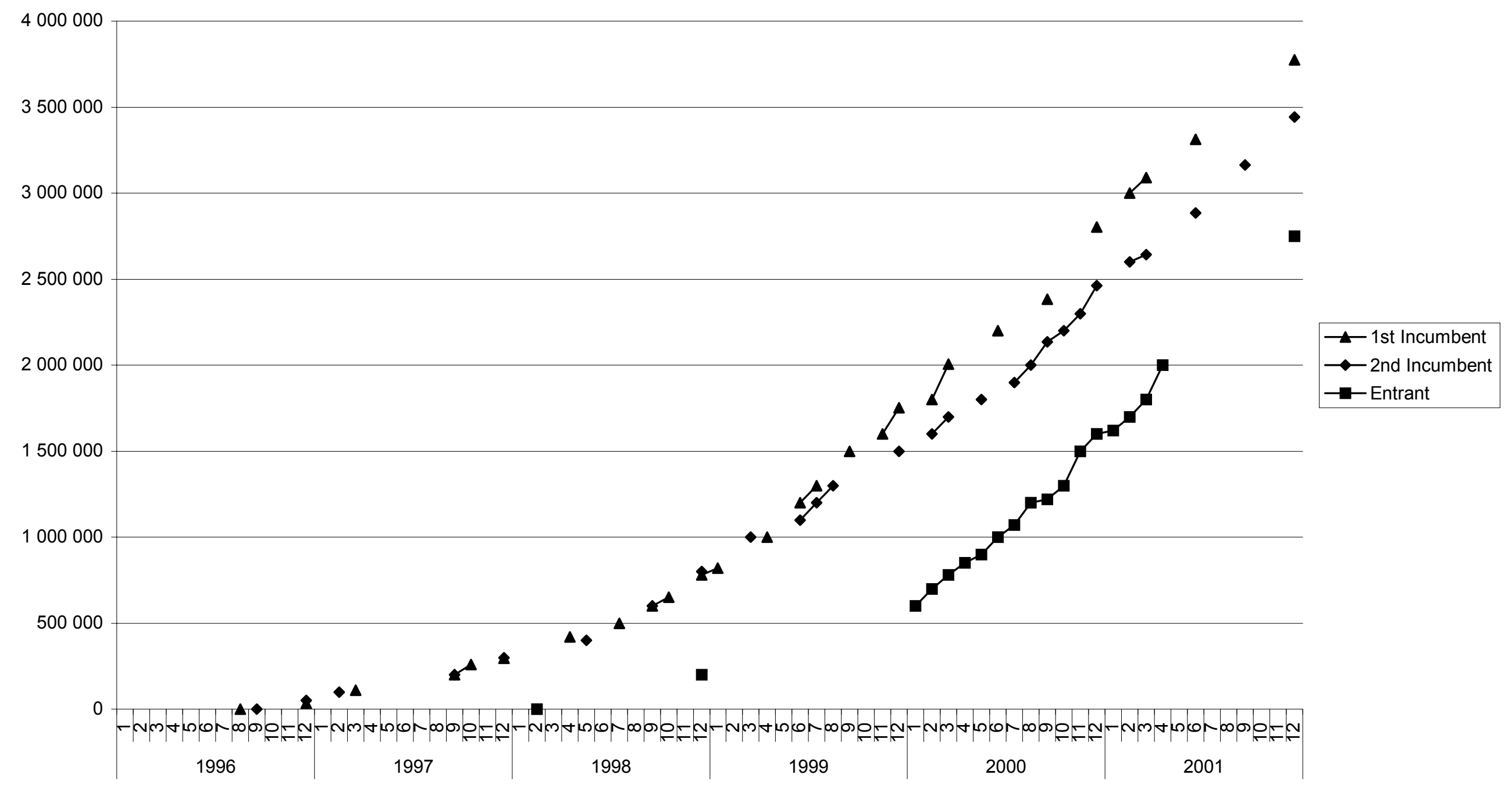


Figure 3. Aggregated steady-state demand in the Polish mobile telephone industry (in millions of subscribers)

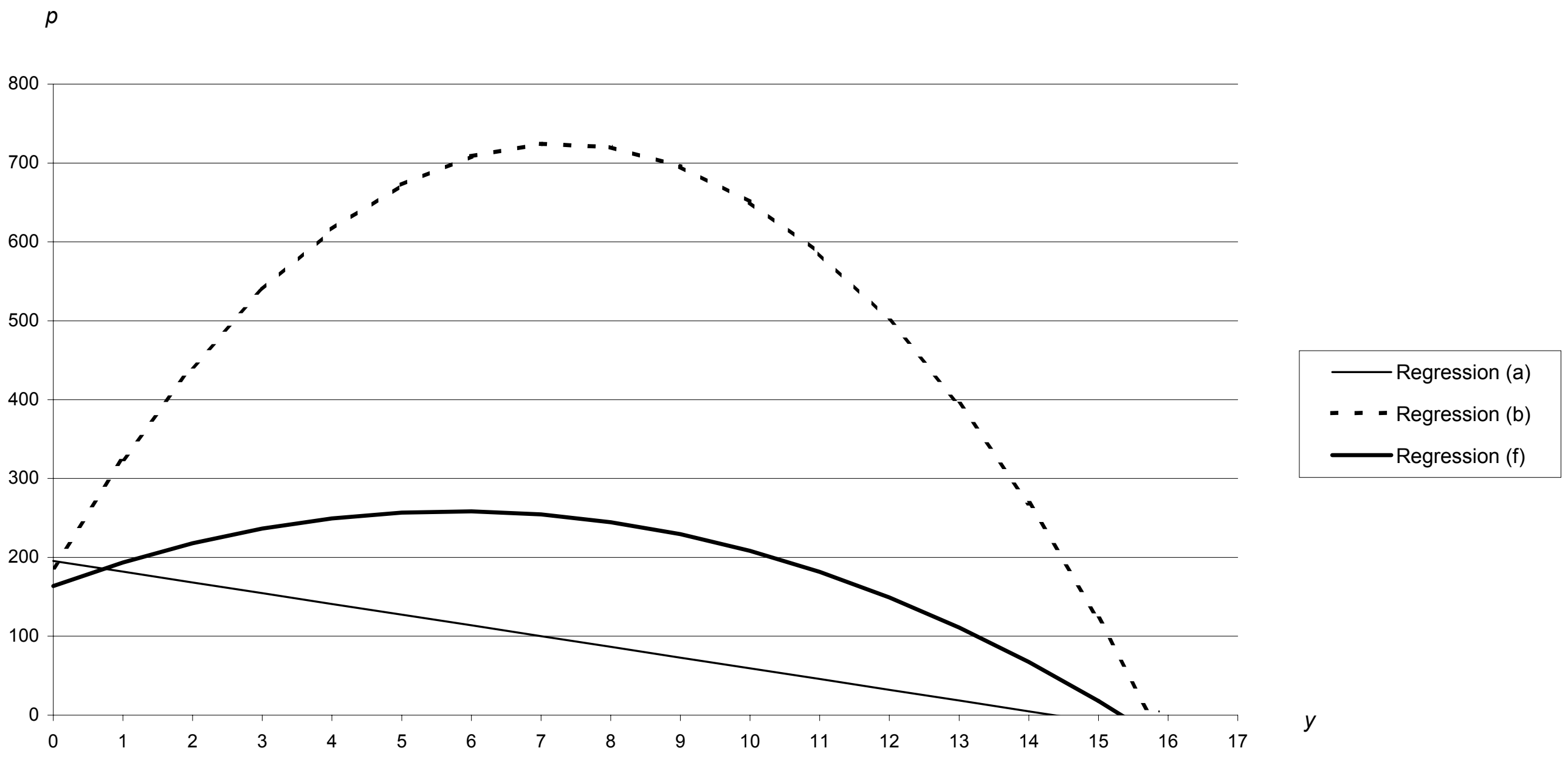


Figure 4. Simulations of the aggregated steady-state demand in the Polish mobile telephone industry for different values of the structural parameters

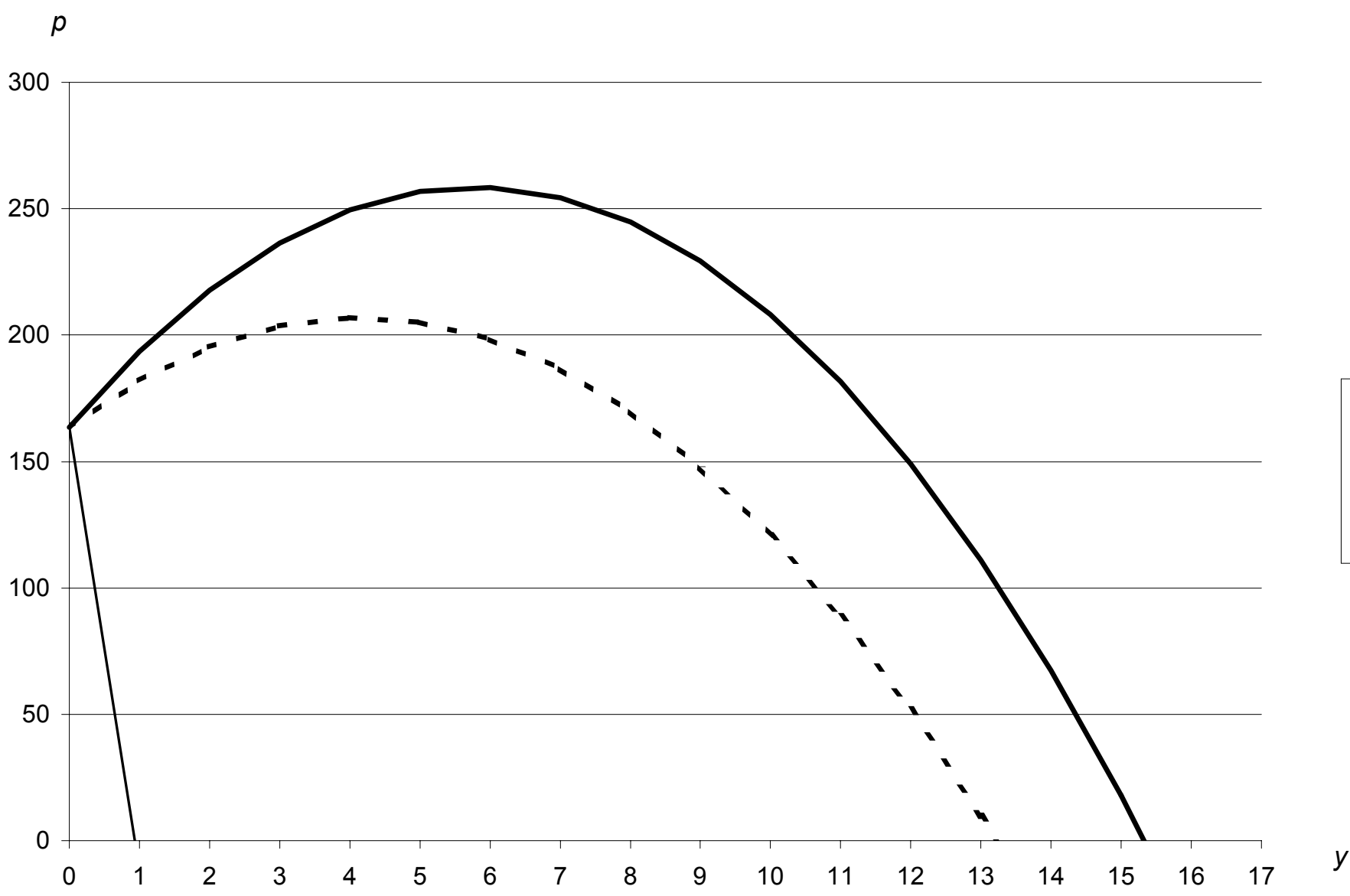

Regression (f); $w=0.125$

- - Regression (f); $w=0.089$

Regression (f); no externalities 


\section{References}

Becker G.S. (1991), “A Note on Restaurant Pricing and Other Examples of Social Influence on Price”, Journal of Political Economy 99(5), 1109-1116.

Beggs A., P. Klemperer (1992), "Multi-period competition with switching costs", Econometrica 60(3), 651-666.

Blonski M. (2002), "Network externalities and two-part tariffs in telecommunication markets", Information Economics and Policy 14, 95-109.

Bousquet A., M. Ivaldi (1997), "Optimal pricing of telephone usage: An econometric implementation", Information Economics and Policy 9(3), 219-239.

Cabral L.M.B. (1990), “On the adoption of innovations with 'network' externalities", Mathematical Social Sciences 19, 299-308.

Dhebar A., S. S. Oren (1985), “Optimal dynamic pricing for expanding networks”, Marketing Science 4(4), 336-351.

Grajek M. (2002), "Identification of Network Externalities in Markets for Non-Durables", Wissenschaftszentrum Berlin, Discussion Paper FS IV 02-32.

Granger C.W.J., T. Teräsvirta (1993), “Modelling Nonlinear Economic Relationships”, Oxford University Press, New York.

Granovatter M., R. Soong (1986), “Threshold model of interpersonal effects in consumer demand", Journal of Economic Behavior and Organization 7, 83-99.

Gruber H., F. Verboven (2001), "The diffusion of mobile telecommunications services in the European Union", European Economic Review 45, 577-588.

Hannan E. J., J. Rissanen (1982), "Recursive estimation of mixed autoregressive-moving average order", Biometrika 69(1), 81-94.

Hatanaka M. (1974), “An efficient two-step estimator for the dynamic adjustment model with autoregressive errors", Journal of Econometrics 2, 199-220.

Katz M. L., C. Shapiro (1994), "Systems Competition and Network Effects", Journal of Economic Perspectives 8(2), 93-115.

Kim H.-S., N. Kwon (2003), "The advantage of network size in acquiring new subscribers: a conditional logit analysis of the Korean mobile telephone market", Information Economics and Policy 15(1), 17-33.

Klemperer P. (1995), “Competition when Consumers have Switching Costs: An Overview wit Applications to Industrial Organization, Macroeconomics and International Trade", Review of Economic Studies 62, 515-539. 
Leibenstein H. (1950), "Bandwagon, snob, and Veblen Effects in the theory of consumers' demand", Quarterly Journal of Economics 64, 183-207.

Lindbeck A., S. Nyberg, and J.W. Weibull (1999), "Social norms and economic incentives in the welfare state", Quarterly Journal of Economics 114(1), 1-35.

Newey W., K. West (1987), “A Simple Positive Semi-Definite, Heteroscedasticity and Autocorrelation Consistent Covariance Matrix”, Econometrica 55(3), 703-708.

OECD Telecommunication Basket Definitions (2000), Teligen, Richmond, U.K.

Okada Y., K. Hatta (1999), "The interdependent telecommunications demand and efficient price structure", Journal of Japanese and International Economies 13(4), 311-335.

Parker P.M., L.-H. Röller (1997), "Collusive conduct in duopolies: multimarket contact and cross-ownership in the mobile telephone industry", RAND Journal of Economics 28(2), 304-322.

Reiss P. C., F. A. Wolak (2002), "Structural econometric modeling: rationales and examples from Industrial Organization", mimeo.

Rohlfs J. (1974), “A theory of interdependent demand for a communications service”, Bell Journal of Economics 5(1), 16-37.

Schoder D. (2000), "Forecasting the success of telecommunication services in the presence of network effects", Information Economics and Policy 12, 181-200.

White H. (1980), “A Heteroscedasticity Consistent Covariance Matrix Estimator and a Direct Test for Heteroscedasticity", Econometrica 48(4), 817-838. 
Bücher des Forschungsschwerpunkts Markt und politische Ökonomie

Books of the Research Area Markets and Political Economy

Sebastian Kessing

Essays on Employment Protection

2003, Freie Universität Berlin,

http://www.diss.fu-berlin.de/2003/202

Daniel Krähmer

On Learning and Information in Markets and

Organizations

2003, Shaker Verlag

Andreas Stephan

Essays on the Contribution of Public Infrastructure to Private: Production and its Political

Economy

2002, dissertation.de

Hans Mewis

Essays on Herd Behavior and Strategic

Delegation

2001, Shaker Verlag

Andreas Moerke

Organisationslernen über Netzwerke - Die personellen Verflechtungen von

Führungsgremien japanischer

Aktiengesellschaften

2001, Deutscher Universitäts-Verlag

Silke Neubauer

Multimarket Contact and Organizational Design

2001, Deutscher Universitäts-Verlag

Lars-Hendrik Röller, Christian Wey (Eds.)

Die Soziale Marktwirtschaft in der neuen

Weltwirtschaft, WZB Jahrbuch 2001

2001, edition sigma

Michael Tröge

Competition in Credit Markets: A Theoretic

Analysis

2001, Deutscher Universitäts-Verlag

Tobias Miarka

Financial Intermediation and Deregulation:

A Critical Analysis of Japanese Bank-Firm-

Relationships

2000, Physica-Verlag

Rita Zobel

Beschäftigungsveränderungen und organisationales Lernen in japanischen Industriengesellschaften

2000, Humboldt-Universität zu Berlin http://dochost.rz.hu-berlin.de/dissertationen/zobelrita-2000-06-19
Jos Jansen

Essays on Incentives in Regulation and

Innovation

2000, Tilburg University

Ralph Siebert

Innovation, Research Joint Ventures, and Multiproduct Competition

2000, Humboldt-Universität zu Berlin

http://dochost.rz.hu-berlin.de/dissertationen/siebertralph-2000-03-23/

Damien J. Neven, Lars-Hendrik Röller (Eds.)

The Political Economy of Industrial Policy in

Europe and the Member States

2000, edition sigma

Jianping Yang

Bankbeziehungen deutscher Unternehmen: Investitionsverhalten und Risikoanalyse

2000, Deutscher Universitäts-Verlag

Christoph Schenk

Cooperation between Competitors -

Subcontracting and the Influence of Information, Production and Capacity on Market Structure and Competition

1999, Humboldt-Universität zu Berlin

http://dochost.rz.hu-berlin.de/dissertationen/schenkchristoph-1999-11-16

Horst Albach, Ulrike Görtzen, Rita Zobel (Eds.)

Information Processing as a Competitive

Advantage of Japanese Firms

1999, edition sigma

Dieter Köster

Wettbewerb in Netzproduktmärkten

1999, Deutscher Universitäts-Verlag

Christian Wey

Marktorganisation durch Standardisierung: Ein

Beitrag zur Neuen Institutionenökonomik des

Marktes

1999, edition sigma

Horst Albach, Meinolf Dierkes, Ariane Berthoin Antal, Kristina Vaillant (Hg.)

Organisationslernen - institutionelle und

kulturelle Dimensionen

WZB-Jahrbuch 1998

1998, edition sigma 
Lars Bergman, Chris Doyle, Jordi Gual, Lars Hultkrantz, Damien Neven, Lars-Hendrik Röller, Leonard Waverman

Europe's Network Industries: Conflicting Priorities - Telecommunications

Monitoring European Deregulation 1

1998, Centre for Economic Policy Research

Manfred Fleischer

The Inefficiency Trap

Strategy Failure in the

German Machine Tool Industry

1997, edition sigma
Christian Göseke

Information Gathering and Dissemination

The Contribution of JETRO to

Japanese Competitiveness

1997, Deutscher Universitäts-Verlag 
Fredrik Andersson

Kai A. Konrad

Lars-Hendrik Röller

Christian Wey

Talat Mahmood Klaus Schömann

Talat Mahmood Klaus Schömann

Jos Jansen

Jos Jansen

Günter Franke Harris Schlesinger Richard C. Stapleton

Tomaso Duso

Johan Lagerlöf

Paul Heidhues

Olivier Cadot Lars-Hendrik Röller Andreas Stephan

Justus Haucap

Christian Wey

Heidrun C. Hoppe Emre Ozdenoren

Rainer Nitsche

Daniel Krähmer

J. Peter Murmann

Kai A. Konrad

Robert Nuscheler

Fredrik Andersson Kai A. Konrad
Human Capital Investment and Globalization in Extortionary States

Merger Control in the New Economy

Die Determinanten der Mirgrationsentscheidung von IT-Hochschulabsolventen aus Pakistan Empirische Befunde zur Ausgestaltung der deutschen „Green Card“

The Determinants of the Migration Decision of ITgraduates from Pakistan: Empirical Evidence for the Design of a German "Green Card"

The Effects of Disclosure Regulation on Innovative Firms: Common Values

The Effects of Disclosure Regulation on Innovative Firms: Private Values

Multiplicative Background Risk

On the Politics of the Regulatory Reform:

Econometric Evidence from the OECD Countries

On the Desirability of an Efficiency Defense in

Merger Control

Contribution to Productivity or Pork Barrel? The Two Faces of Infrastructure Investment

Unionization Structures and Firms' Incentives for Productivity Enhancing Investments

Intermediation in Innovation

On the Effectiveness of Anti-Predation Rules

Entry and Experimentation in

Oligopolistic Markets for Experience Goods

The Coevolution of Industries and National Institutions: Theory and Evidence

Terrorism and the State

Physician Reimbursement, Time-Consistency and the Quality of Care

Taxation and Education Investment in the Tertiary Sector
FS IV $02-06$

FS IV $02-11$

FS IV $02-12$

FS IV $02-15$

\author{
FS IV $02-02$ \\ FS IV $02-01$ \\ FS IV $02-03$
}

FS IV $02-03 a$

FS IV $02-04$

FS IV $02-05$

FS IV $02-07$

FS IV $02-08$

FS IV $02-09$

FS IV $02-10$

FS IV $02-13$

FS IV $02-14$

FS IV $02-16$

FS IV $02-17$ 
Jan Boone

Helmut Bester

Kai A. Konrad

Kjell Erik Lommerud Bjørn Sandvik

Odd Rune Straume

Steffen Huck Vicki Knoblauch Wieland Müller

Ralph Siebert

Jürgen Bracht

Saul Lach

Eyal Winter

Steffen Huck

Kai A. Konrad

Daniel Krähmer

Thomas Knaus

Robert Nuscheler

Kurt R. Brekke

Robert Nuscheler

Odd Rune Straume

Kai A. Konrad

Sebastian Kessing

Sebastian Kessing

Michal Grajek

Robert M. Adams Lars-Hendrik Röller

Robin C. Sickles

Tomaso Duso

Damien J. Neven Lars-Hendrik Röller

Tomaso Duso Astrid Jung
'Be nice, unless it pays to fight': A New Theory of

Price Determination with Implications for

Competition Policy

Altruism and Envy in Contests:

FS IV $02-19$

An Evolutionarily Stable Symbiosis

Delay in Contests

FS IV $02-20$

Good Jobs, Bad Jobs and Redistribution

FS IV $02-21$

On the Profitability of Collusion in Location Games

FS IV $02-22$

Learning by Doing and Multiproduction Effects over the Life Cycle: Evidence from the Semiconductor Industry

Modeling Oligopolistic Price Adjustment in Micro Level Panel Data

Strategic Trade Policy and the Home Bias in Firm Ownership Structure

Delegation versus Authority

FS IV $02-26$

Incomplete Risk Adjustment and Adverse

FS IV $02-27$

Selection in the German Public Health Insurance System

Quality and Location Choices under Price Regulation

FS IV $02-28$

Inverse Campaigning

FS IV $02-29$

A Note on the Determinants of Labour Share Movements

Employment Protection and Product Market Competition

Identification of Network Externalities in Markets for Non-Durables

Market Power in Outputs and Inputs: An Empirical Application to Banking

The Political Economy of European Merger Control: Evidence using Stock Market Data

Market Conduct and Endogenous Lobbying: Evidence from the U.S. Mobile Telecommunications Industry
FS IV $02-34$

FS IV $02-30$

FS IV $02-31$

FS IV $02-32$

FS IV $02-33$

FS IV $02-35$ 
Annette Boom

Kai A. Konrad Wolfram F. Richter

Stergios Skaperdas

Johan Lagerlöf

Roman Inderst

Christian Wey

Sebastian Kessing

Robert Nuscheler

Lars Frisell

Paul Heidhues Nicolas Melissas

Pablo Beramendi

Daniel Krähmer

Ralph Siebert

Vivek Ghosal

Vivek Ghosal

Andreas Blume

Paul Heidhues

Sebastian Kessing

Tomaso Duso Astrid Jung

Thomas R. Cusack Pablo Beramendi

Kjell Erik Lommerud Frode Meland Odd Rune Straume
Investments in Electricity Generating Capacity under Different Market Structures and with Endogenously Fixed Demand

Zur Berücksichtigung von Kindern bei umlagefinanzierter Alterssicherung

Restraining the Genuine Homo Economicus: Why the Economy cannot be divorced from its Governance

Insisting on a Non-Negative Price: Oligopoly, Uncertainty, Welfare, and Multiple Equilibria

Buyer Power and Supplier Incentives

SP II $2003-02$

SP || $2003-03$

SP || $2003-04$

SP II $2003-05$

Monopoly Pricing with Negative Network Effects:

The Case of Vaccines

The Breakdown of Authority

SP || $2003-07$

Equilibria in a Dynamic Global Game: The Role of Cohort Effects

Political Institutions and Income Inequality:

The Case of Decentralization

Learning and Self-Confidence in Contests

SP || $2003-10$

SP || $2003-11$ Incumbent Firms: Market Proliferation versus Cannibalization

Impact of Uncertainty and Sunk Costs on Firm Survival and Industry Dynamics

Endemic Volatility of Firms and Establishments:

Are Real Options Effects Important?

Private Monitoring in Auctions

SP || $2003-14$

Delay in Joint Projects

SP || $2003-15$

Product Market Competition and Lobbying

SP || $2003-16$

Coordination in the U.S. Mobile

Telecommunications Industry

Taxing Work: Some Political and Economic

SP || $2003-17$ Aspects of Labor Income Taxation

Globalisation and Union Opposition to Technological Change
SP || $2003-18$ 
Joseph Clougherty

Dan Anderberg Fredrik Andersson

Eugenio J. Miravete Lars-Hendrik Röller

Talat Mahmood Klaus Schömann

Talat Mahmood Klaus Schömann

Suchan Chae Paul Heidhues

Sigurt Vitols

Michal Grajek
Industry Trade-Balance and Domestic Merger

Policy: Some Empirical Evidence from the U.S.

Stratification, Social Networks in the Labour Market, and Intergenerational Mobility

Estimating Markups under Nonlinear Pricing Competition

On the Migration Decision of IT-Graduates:

A Two-Level Nested Logit Model

Assessing the Migration Decision of Indian IT-Graduates: An Empirical Analysis

Buyers Alliances for Bargaining Power

Negotiated Shareholder Value: The German Version of an Anglo-American Practice

Estimating Network Effects and Compatibility in Mobile Telecommunications
SP || $2003-19$

SP II $2003-20$

SP || $2003-21$

SP || $2003-22$

SP || $2003-23$

SP || $2003-24$

SP || $2003-25$

SP || $2003-26$ 
Bei Ihren Bestellungen von WZB-Papers schicken

Sie bitte unbedingt einen an Sie adressierten Auf-

kleber mit sowie je paper eine Briefmarke im Wert

von 0,51 Euro oder einen "Coupon Reponse Inter-

national " (für Besteller aus dem Ausland)
Please send a self addressed label and postage stamps in the amount of 0.51 Euro or a "CouponReponse International" (if you are ordering from outside Germany) for each WZB-paper requested

Absender / Return Address:

Wissenschaftszentrum Berlin

für Sozialforschung

Presse- und informationsreferat

Reichpietschufer 50

D-10785 Berlin-Tiergarten

Hiermit bestelle ich folgende(s)

Discussion paper(s):

Please send me the following Discussion paper(s):

Bestell-Nr. / Order no.

Autor/in, Kurztitel /Author(s) / Title(s) in brief 